\title{
Long non-coding RNA AC245100.4 promotes prostate cancer tumorigenesis via the microRNA-145-5p/RBBP5 axis
}

\author{
HUI XIE ${ }^{1,2^{*}}$, JIABIN ZHAO $^{1,3^{*}}$, JIAHUI WAN $^{1}$, JIANING ZHAO $^{1}$, QIANQIAN WANG ${ }^{1}$, \\ XU YANG ${ }^{1}$, WEIYU YANG ${ }^{1}$, PING LIN $^{1}$ and XIAOGUANG YU ${ }^{1}$ \\ ${ }^{1}$ Department of Biochemistry and Molecular Biology; ${ }^{2}$ Teaching Experiment Center of Biotechnology, \\ Harbin Medical University, Harbin, Heilongjiang 150086; ${ }^{3}$ Department of Emergency Surgery, \\ The First Affiliated Hospital of Harbin Medical University, Harbin, Heilongjiang 150001, P.R. China
}

Received April 13, 2020; Accepted October 5, 2020

DOI: $10.3892 /$ or.2020.7894

\begin{abstract}
Long non-coding RNAs (lncRNAs) are markedly involved in cancer progression. Thus, identification of these lncRNAs can aid in the treatment of cancer. The present study focused on investigating the overall biological function, mechanism of action and clinical importance of lncRNA AC245100.4 in prostate cancer (PCa). The present study identified that AC245100.4 expression was significantly upregulated in PCa tissues and cell lines. Knockdown of AC245100.4 impaired tumor growth in an animal model. Biological function analysis indicated that AC245100.4 overexpression notably promoted cell proliferation and migration, while knockdown of AC245100.4 suppressed cell proliferation and migration. Mechanism studies focused on the competing endogenous RNA (ceRNA) network of AC245100.4. Bioinformatics predictions indicated that both AC245100.4 and retinoblastoma binding protein 5 (RBBP5) had microRNA (miR) response elements for miR-145-5p. This was further verified using a dual luciferase and RNA immunoprecipitation assays. AC245100.4 could positively regulate RBBP5 expression, but negatively regulated miR-145-5p expression. In addition, AC245100.4 knockdown-mediated inhibitory effects on cell proliferation and migration could be reversed by miR-145-5p silencing. Overall, the present study proposed a novel model in which the AC245100.4/miR-145-5p/RBBP5 ceRNA network
\end{abstract}

Correspondence to: Professor Xiaoguang Yu or Professor Ping Lin, Department of Biochemistry and Molecular Biology, Harbin Medical University, 157 Baojian Road, Harbin, Heilongjiang 150086, P.R. China

E-mail: yxg301@163.com

E-mail: 1p1995hyd@126.com

*Contributed equally

Key words: long non-coding RNA AC245100.4, microRNA-145-5p, retinoblastoma binding protein 5 , competing endogenous RNA, prostate cancer induced the development of PCa, providing novel insights for PCa treatment.

\section{Introduction}

Prostate cancer (PCa) has accounted for the largest number of estimated new cases of cancer among men (2018-2020) in the United States, and the number of mortalities was the second highest, accounting for $10 \%$ of all mortalities (1-3). Globally, the number of diagnosed cases of PCa in men is the highest among all cancer types in 109 countries (4). Although therapeutic strategies have improved over time, the efficiency remains far from optimal. Researchers have focused on the regulatory role of protein-coding RNAs. Recently, numerous non-coding RNAs (ncRNAs), including long ncRNAs (lncRNAs), have been revealed to be involved in PCa progression $(5,6)$. Therefore, there is an urgent need to identify the underlying mechanisms of these regulatory transcripts to fully understand PCa carcinogenesis in order to develop novel diagnostic targets and treatment strategies.

lncRNAs are a subset of ncRNAs with a transcription length of $>200$ nucleotides, and have limited or no protein coding ability (7). Moreover, IncRNAs exhibit both the highest abundance and complexity among non-coding transcripts (8). Numerous studies have reported that lncRNAs achieve their regulatory role by regulating gene expression at the transcriptional or post-transcriptional level $(5,6,9)$. Salmena et al $(10)$ proposed a novel regulatory mechanism, in which lncRNAs regulate mRNA expression by competing with microRNAs (miRNAs/miRs), forming a competing endogenous RNA (ceRNA) network. A large number of ceRNA regulatory networks are involved in cancer development. For example, lnc-TALC promotes O-6-methylguanine-DNA methyltransferase expression and temozolomide resistance by regulating the c-Met/STAT3/p300 axis via sponging of miR-20b-3p in glioblastoma (11). IncRNA-PAGBC contributes to gallbladder cancer development by regulating miR-511 as a ceRNA (12), while LINC81507 acts as tumor suppressor by competing with miR-199b-5p to regulate caveolin 1 expression and STAT3 activation in non-small cell lung cancer (NSCLC) (13). In $\mathrm{PCa}$, several lncRNAs have been demonstrated to contribute to tumorigenesis as ceRNAs. For instance, the highly specific 
lncRNA prostate cancer associated 3 (PCA3) exerts an oncogenic effect by competitively binding with miR-218-5p and promoting high mobility group box 1 expression in $\mathrm{PCa}$ (14). It has also been revealed that forkhead box P4 (FOXP4)-antisense RNA 1 regulates FOXP4 at the post-transcriptional level by sponging miR-3184-5p to promote tumorigenesis (15), while IncRNA small nucleolar RNA host gene 12 promotes cancer cell proliferation and metastasis by sponging miR-133b (16). Therefore, it was hypothesized that other lncRNAs may also be involved in PCa progression by acting as ceRNAs.

Our previous study identified that lncRNA AC245100.4 (ENSG00000231551 or RP11-495P10.1) was closely associated with PCa (17). However, whether it had clinical significance, the exact role it served in cancer progression and its mechanism of action remain to be revealed in PCa. Therefore, it is necessary to investigate the relationship between AC245100.4 and PCa. In the present study, the expression of AC245100.4 in patients with PCa was examined via bioinformatics prediction. Cell proliferation assay, Transwell migration assay, wound healing and subcutaneous models were used for assessing the role of AC245100.4 in PCa. Moreover, the underlying mechanisms were evaluated.

\section{Materials and methods}

Cell source and culture condition. The human normal prostate epithelium cell line (RWPE1), PCa cell lines (DU145 and PC3) and 293T cells were all purchased from The Cell Bank of Type Culture Collection of the Chinese Academy of Sciences. RWPE1 cells were cultured in keratinocyte-serum-free medium containing $0.05 \mathrm{mg} / \mathrm{ml}$ bovine pituitary extract and $5 \mathrm{ng} / \mathrm{ml}$ epidermal growth factor (all from Gibco; Thermo Fisher Scientific, Inc.). DU145 cells were maintained in RPMI 1640 medium (Invitrogen; Thermo Fisher Scientific, Inc.), while PC3 and 293T cells were cultured in DMEM (Invitrogen; Thermo Fisher Scientific, Inc.). All culture media were supplemented with 10\% FBS (Gibco; Thermo Fisher Scientific, Inc.) and 1\% penicillin/streptomycin (Sigma Aldrich; Merck $\mathrm{KGaA}$ ). All cells were maintained in a humidified atmosphere at $37^{\circ} \mathrm{C}$ with $5 \% \mathrm{CO}_{2}$.

Bioinformatics analysis. The different expression of AC245100.4 in prostate cancer and healthy tissues were analyzed via Gene Expression Profiling Interactive Analysis (GEPIA; version: 1.0; http://gepia.cancer-pku.cn/), using data from The Cancer Genome Atlas (TCGA) database (18). The data included 492 PCa tissues (tumor) and 52 adjacent para-cancerous tissues (healthy). Relative analysis values were selected as follows: Gene=ENSG00000231551 or RP11-495P10.1; $\log 2 \mathrm{FCl}$ cutoff=0.05; P-value cutoff=0.05; datasets $=$ Prostate adenocarcinoma and match TCGA normal data.

Gene transfection in vitro. The overexpression pcDNA3.1AC245100.4 and control pcDNA3.1 recombinant plasmids were constructed by Shanghai GenePharma Co., Ltd. Small interfering RNAs [si-AC245100.4 and si-negative control (NC)] and miRNAs [(mimics-miR-145-5p, mimic-NC; cat. no. miR10000437) and (inhibitors-miR-145-5p and inhibitor-NC; cat. no. miR20000437)] were synthesized by
Guangzhou RiboBio Co., Ltd. The siRNA sequences were as follows: si-NC, 5'-UUCUCCGAACGUGUCACGUTT-3'; si-AC245100.4-\#1, 5'-UCAGAUCAGAACUAGCUAUTT-3'; si-AC245100.4-\#2, 5'-GGAUUGUAUAUGUCCUCUUTT-3'; and si-AC245100.4-\#3, 5'-GUCCAGCUGUAUAAUGAA ATT-3'. Lipofectamine ${ }^{\circledR} 2000$ (Thermo Fisher Scientific, Inc.) was used for gene transfection following the manufacturer's instructions. Cells were transfected with $100 \mathrm{nM}$ miRNAs (miR-145-5p mimics or inhibitors), $50 \mathrm{nM}$ siRNA (si-AC245100.4 or si-NC) or $2 \mu \mathrm{g}$ plasmid for $24 \mathrm{~h}$ in 6 -well plates. Transfection procedures were conducted at room temperature. Cell proliferation assay were performed $24 \mathrm{~h}$ post-transfection. Reverse transcription-quantitative (RT-q) PCR, RNA immunoprecipitation (RIP) assay, scratch wound healing assay and Transwell migration assay were conducted $48 \mathrm{~h}$ post-transfection. Western blotting was performed $72 \mathrm{~h}$ post-transfection.

$R T-q P C R$. Total RNA was isolated using RNAiso Plus reagent (Takara Bio, Inc.) according to the manufacturer's protocol. RNA concentration and purity were detected using a NanoDrop 2000 (Thermo Fisher Scientific, Inc.). Subsequently, $1 \mu \mathrm{g}$ total RNA was transcribed to cDNA using the PrimeScript ${ }^{\mathrm{TM}}$ RT reagent kit (Takara Bio, Inc.). RT reaction were two steps: gDNA eraser at $42^{\circ} \mathrm{C}$ for $2 \mathrm{~min}$, reverse transcription at $37^{\circ} \mathrm{C}$ for $15 \mathrm{~min}$ and $85^{\circ} \mathrm{C}$ for $5 \mathrm{sec}$. RT-qPCR was performed according to the manufacturer's protocol using SYBR Premix Ex Taq II (Takara Bio, Inc.). Reaction conditions were set as: Initial denaturation at $95^{\circ} \mathrm{C}$ for $1 \mathrm{~min}$, followed by 40 cycles of $95^{\circ} \mathrm{C}$ for $5 \mathrm{sec}$ and $60^{\circ} \mathrm{C}$ for $10 \mathrm{sec}$. Relative RNA expression was analyzed based on the $2^{-\Delta \Delta \mathrm{Cq}}$ method and GAPDH was used as an internal control for the $\Delta \mathrm{Cq}$ of specific genes (19). The primers used were as follows: GAPDH forward, 5'-GAG TCAACGGATTTGGTCGT-3' and reverse, 5'-GACAAGCTT CCCGTTCTCAG-3'; RBBP5 forward, 5'-AGACAAAAATTA GCTGGGCGTGG-3' and reverse, 5'-GTGGTGCGATTC TCCACTCACT-3'; and AC245100.4 forward, 5'-AGCAAT GCCTTCCTCTTTGA-3' and reverse, 5'-AAGGGTCTCCTT CAGGTGCT-3'. The primers for miR-145-5p were provided along with the miRNAs synthesized by Guangzhou RiboBio Co., Ltd. (cat. no. miR10000437).

Western blotting. Whole cell lysates were obtained by lysing cells using RIPA buffer (Beyotime Institute of Biotechnology) with proteinase inhibitor (Sigma-Aldrich; Merck KGaA) on ice. The concentrations of isolated proteins were detected using a BCA assay kit (Beyotime Institute of Biotechnology). Equal amounts of whole cell lysate $(50 \mu \mathrm{g})$ were subjected to $10 \%$ SDS-PAGE. Subsequently, proteins in the gel were transferred to PVDF membranes (EMD Millipore). Following blocking with $5 \%$ non-fat milk for $2 \mathrm{~h}$ at room temperature, the membranes were incubated with specific primary antibodies against RBBP5 (cat. no. 13171; 1:1,000) or GAPDH (cat. no. $5174 ; 1: 1,000$ ) at $4^{\circ} \mathrm{C}$ overnight. Subsequently, the membranes were incubated with horseradish peroxidase-linked secondary antibodies (cat. no. 7074; 1:3,000) for $1 \mathrm{~h}$ at room temperature. All antibodies were obtained from Cell Signaling Technology, Inc. The blots were visualized using the substrate BeyoECL Plus (Beyotime Institute of Biotechnology) and imaged using a Tanon 5200 Chemiluminescent Imaging 
system (Tanon Science and Technology Co., Ltd.). The densitometry was conducted using ImageJ software, version 1.50 (National Institutes of Health).

RIP assay. RIP was performed according to the manufacturer's protocol of the Magna Nuclear RIP ${ }^{\text {TM }}$ (Cross-Linked) Nuclear RNA-Binding Protein Immunoprecipitation kit (EMD Millipore). PC3 cells $\left(2 \times 10^{7}\right)$ transfected with indicated genes were harvested and lysed on ice. Crosslinking of protein and RNAs were obtained by adding $37 \%$ formaldehyde at room temperature for $10 \mathrm{~min}$. Excess formaldehyde was removed using glycine and cell pellets were centrifugated at $800 \mathrm{x}$ g for $5 \mathrm{~min}$ at $4^{\circ} \mathrm{C}$. Subsequently, cell pellets were incubated with the Nuclei Isolation Buffer on ice for 15 min. RIP Cross-linked Lysis Buffer was then added to release the cross-linked protein/RNAs. The lysate was sonicated with 5 pulses at $50 \%$ power with $30 \mathrm{sec}$ intervals between pulses using SM-250D (Nanjing Shunma Technology Co., Ltd.). The tubes were cooled on ice at all times. Specific argonaute RNA-induced silencing complex (RISC) catalytic component 2 (AGO2; cat. no. MA5-14861; 1:10; Thermo Fisher Scientific, Inc.) or IgG antibodies (cat. no. PP64B; 1:10; EMD Millipore) were incubated with Protein A/G magnetic beads (supplied in the kit) at $4^{\circ} \mathrm{C}$ for $\sim 3 \mathrm{~h}$ to obtain conjugated beads. Mix the conjugated beads with sonicated lysis and incubate in $4^{\circ} \mathrm{C}$. The beads were washed with ice cold low Salt Wash Buffer after 3 h. Protein in beads was removed using Proteinase K. Finally, the existence of AC245100.4 or miR-145-5p in immunoprecipitated RNA was analyzed by qPCR.

Cell proliferation assay. A Cell Counting Kit 8 (CCK8; Beyotime Institute of Biotechnology) was used to evaluate cell proliferation according to the manufacturer's instructions. DU145 or PC3 cells after gene transfection with AC245100.4 or miR-145-5p were collected and counted separately. Cells were seeded at a density of 5,000 cells/well in 96-well plates. Following incubation for 1-4 days CCK8 solution was added in the dark at a volume of $10 \%$ of the cell suspension. Subsequently, the plate was incubated at $37^{\circ} \mathrm{C}$ for another $1 \mathrm{~h}$. The absorbance at a wavelength of $450 \mathrm{~nm}$ was measured using a microplate reader.

Cell migration analysis. Both scratch wound healing and Transwell migration assays were used to evaluate the cell migratory ability as previously described (20). For the scratch wound healing assay, DU145 and PC3 cells were scratched using a $200 \mu \mathrm{l}$ tip at $48 \mathrm{~h}$ after gene transfection. Cells were washed and cultured in serum-free medium after scratching. Images of wound were captured with light microscope (magnification, $\mathrm{x} 200)$ at 0 and $24 \mathrm{~h}$ post scratching. The blank area between cell boundaries at $0 \mathrm{~h}$ (Area 0 ) and $24 \mathrm{~h}$ (Area 24) was quantitated using ImageJ software, version 1.50 (National Institutes of Health). The migration rates were calculated by the formula: [(Area 0)-(Area 24)]/(Area 0) x100\%.

For the Transwell migration assay, cells $\left(5 \times 10^{5}\right.$ cells $\left./ \mathrm{ml}\right)$ in $200 \mu \mathrm{l}$ serum-free medium were seeded in the top chambers of 8- $\mu \mathrm{m}$ pore size Transwell inserts (Corning Inc.). A total of $600 \mu \mathrm{l}$ medium supplemented with $20 \%$ FBS was added to the bottom Transwell chamber. After $24 \mathrm{~h}$ of incubation at $37^{\circ} \mathrm{C}$, the cells on the membrane of the top inserts were fixed with
$100 \%$ ethanol at room temperature for $15 \mathrm{~min}$ and stained with $0.5 \%$ crystal violet for $20 \mathrm{~min}$ at room temperature. Cell numbers were counted in $\geq 6$ random fields with light microscope at $\times 20$ magnification for the Transwell migration assays.

Luciferase reporter assay. The binding sites between AC245100.4 and miR-145-5p were predicted using the online DIANA-LncBase version: v2.0 (https://diana.e-ce. uth.gr/home), while TargetScan version 7.2 (http://www. targetscan.org/vert_72/) and miRDB version 1 (http://www. mirdb.org/) were used to predict binding sites between RBBP5 and miR-145-5p (21-23). The wild-type (WT) plasmids were produced by inserting the predicted binding site in the AC245100.4 sequence and the 3'untranslated region (3'UTR) of RBBP5 into the psi-CHECK-2 vector (Promega Corporation). Simultaneously, the predicted binding site was deleted to generate mutant (MUT) plasmids. 293T cells $\left(1 \times 10^{6}\right)$ were co-transfected with the WT or MUT plasmids ( $2 \mu \mathrm{g}$ in 6-well plates) along with miR-145-5p mimic or control using Lipofectamine ${ }^{\circledR} 2000$ (Thermo Fisher Scientific, Inc.) at room temperature. Following $48 \mathrm{~h}$ of incubation after transfection, luciferase activity was evaluated using a Dual-luciferase Reporter assay system (Promega Corporation). The activity of Renilla luciferase was used for the normalization of firefly luciferase activity.

Nude mouse PCa subcutaneous models. All animal experiment protocol and procedure were approved by the Animal Care and Use Committee of Harbin Medical University. The pGPH1-short hairpin RNA (shRNA) plasmids to knockdown AC245100.4 (sh-AC245100.4 or sh-NC) were constructed by Shanghai GenePharma Co. Ltd. A total of $2 \mu \mathrm{g}$ sh-AC245100.4 or sh-NC plasmids were transfected to PC3 cells using Lipofectamine ${ }^{\circledR} 2000$ (Thermo Fisher Scientific, Inc.) at room temperature. Cells were incubated for another $48 \mathrm{~h}$. Then, $2 \mathrm{mg} / \mathrm{ml}$ neomycin was added to PC 3 cells after transfection with sh-AC245100.4 or sh-NC for 2-3 weeks to generate a stable AC245100.4-knockdown PC3 cell line. PCa xenograft models were established via subcutaneous injection of PC 3 cells $\left(1 \times 10^{6}\right.$ cells in $100 \mu 1$ PBS) stably transfected with control shRNA or shRNA-AC245100.4 into male BALB/c nude mice (Beijing Vital River Laboratory Animal Technology Co., Ltd. age, 4-6 weeks; weight, 20-30 g). Cells were subcutaneously injected to the left medial upper limb of mice. Animals were housed at constant temperature $\left(20-26^{\circ} \mathrm{C}\right)$ and humidity $(40-70 \%)$ with a $12 \mathrm{~h}$ dark-light cycle and unrestricted access to food and water. A total of 15 mice were purchased, of which three were excluded from the experiment as one animal died before subcutaneous injection (autopsy did not determine the cause of mortality) and two animals died during anesthesia. A total of 12 mice left were randomly divided into two groups (shRNA-NC or shRNA-AC245100.4; $n=6$ per group). The mice weight and condition were monitored every 2 days. The humane endpoints used to determine when animals should be euthanized were as follows: Weight loss of $20-25 \%$ of the animal's original body weight; loss of appetite for $24 \mathrm{~h}$; severe infection; tumors growth $>10 \%$ of the animal's original body weight or the average diameter $>20 \mathrm{~mm}$; and animals 
that are weak or dying. After 28 days of subcutaneous injection, all 12 tumor-bearing mice lived and were euthanized via excessive anesthetized with an intraperitoneal injection of $0.7 \%$ pentobarbital sodium $(150 \mathrm{mg} / \mathrm{kg})$. After the mice died, which was confirmed by cardiac arrest and respiratory arrest for $>2$ min, tumor samples were excised and weighed. Tumor length and width were measured. Tumor volume was calculated using the formula: $\mathrm{V}=\left(\right.$ length $\mathrm{x}$ width $\left.{ }^{2}\right) / 2$.

Statistical analysis. Each experiment was performed $\geq 3$ times. Data are presented as the mean $\pm \mathrm{SD}$ of $\geq 3$ separate experiments. Differences between two groups were compared using an unpaired two-tailed Student's t-test, and one-way ANOVA followed by Tukey's post hoc test was used to compare differences among multiple groups. The differences in AC245100.4 expression from TCGA database were analyzed using GEPIA (version: 1.0; http://gepia. cancer-pku.cn/) using the method one-way ANOVA for differential analysis. Disease state (Tumor or Normal) was the variable for calculating differential expression. Statistical analysis was performed using GraphPad Prism version 7 (GraphPad Software, Inc.). $\mathrm{P}<0.05$ was considered to indicate a statistically significant difference.

\section{Results}

IncRNA AC245100.4 expression is upregulated in PCa cells. Since AC245100.4 has rarely been investigated in cancer, the present study first examined the association between AC245100.4 and PCa. The differences in AC245100.4 expression were analyzed by GEPIA using data from TCGA database (18). The data included 492 PCa tissues (tumor) and 52 adjacent para-cancerous tissues (healthy). Relative expression values of AC245100.4 were analyzed using $\log 2$ fold changel cut-off $=0.05, \mathrm{P}<0.05$. The difference analysis (Fig. 1A) demonstrated that the expression of AC245100.4 in PCa tissues was increased compared with those in adjacent healthy tissues. Furthermore, the expression of AC245100.4 in PCa cell lines was examined using RT-qPCR. DU145 and PC3 cells exhibited significantly higher expression levels of AC245100.4 compared with the normal prostate epithelium RWPE1 cell line (Fig. 1B). The present results suggested that AC245100.4 expression may be positively associated with the development of PCa.

IncRNA AC245100.4 promotes PCa cell proliferation. The present study investigated the effects of AC245100.4 on cell proliferation in PCa. AC245100.4 expression in DU145 and PC 3 cells was altered by transfection with siRNA and pcDNA3.1/AC245100.4 (Fig. 2A). The RT-qPCR results demonstrated that AC245100.4 expression was effectively regulated in DU145 and PC3 cells. siRNA\#3 was selected for the subsequent experiments due to its high efficiency. The CCK8 proliferation assay results demonstrated that AC245100.4 knockdown decreased proliferation, whereas AC245100.4 overexpression significantly increased proliferation in DU145 and PC3 cells (Fig. 2B-D).

To further investigate the effects of AC245100.4 in vivo, a PC3 cell line with stable knockdown of AC245100.4 was constructed using shRNA (Fig. 2E). Animal models

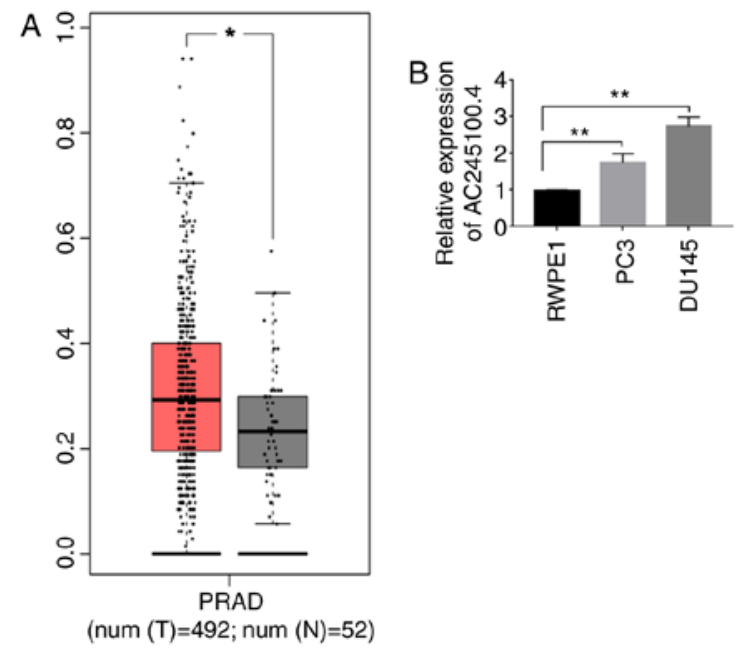

Figure 1. AC245100.4 expression is upregulated in PCa cell lines and tissues. (A) Relative AC245100.4 expression was detected in PCa tissues in The Cancer Genome Atlas database. ${ }^{*} \mathrm{P}<0.05$. (B) Reverse transcription-quantitative PCR was used to analyze the expression of AC245100.4 in a normal prostate epithelial cell line (RWPE1) and prostate cancer cells. Data are presented as the mean $\pm \mathrm{SD}$ of three independent experiments $(n=3) .{ }^{* *} \mathrm{P}<0.01$. PRAD, prostate; num(T), number(Tumor); num(N), number(Normal); PCa, prostate cancer.

were established via subcutaneous injection of control shRNA-treated or shRNA-AC245100.4-treated PC3 cells in male nude mice. It was found that tumor volume and weight were significantly decreased following AC245100.4 knockdown (Fig. 2F). These results suggested that AC245100.4 may promote the proliferation of $\mathrm{PCa}$ cells.

IncRNA AC245100.4 promotes PCa cell migration in vitro. Cancer cell motility reflects the metastasis potential of cancer (24). Subsequently, the present study evaluated the migration abilities of DU145 and PC 3 cells following AC245100.4 knockdown or overexpression. Transwell migration (Fig. 3A) and wound healing (Fig. 3B) assays indicated that AC245100.4 knockdown impaired the migration of PCa cells, while overexpression of AC245100.4 significantly increased the migratory capacity of PCa cells (Fig. 3). Based on its promoting effects on proliferation and migration, it was concluded that AC245100.4 served an oncogenic role in PCa.

IncRNA AC245100.4 targets miR-145-5p in PCa cells. Since it was proposed that AC245100.4 may be an oncogene, its mechanism of action was subsequently investigated. It was identified that AC245100.4 was mostly located in the cytoplasm (data not shown). It has been reported that lncRNAs may be involved in post-transcriptional regulation of mRNAs by sponging miRNAs in human cancer (6). Potential miRNA binding sites in AC245100.4 were predicted using a human miRNA target tool (DIANA Tools) (23). Binding sites with miR-145-5p were observed (Fig. 4A). Therefore, the present study targeted miR-145-5p for further investigation. Following AC245100.4 knockdown, miR-145-5p expression was significantly increased. Conversely, overexpression of AC245100.4 decreased miR-145-5p expression (Fig. 4B). Transfection with miR-145-5p inhibitor could significantly 

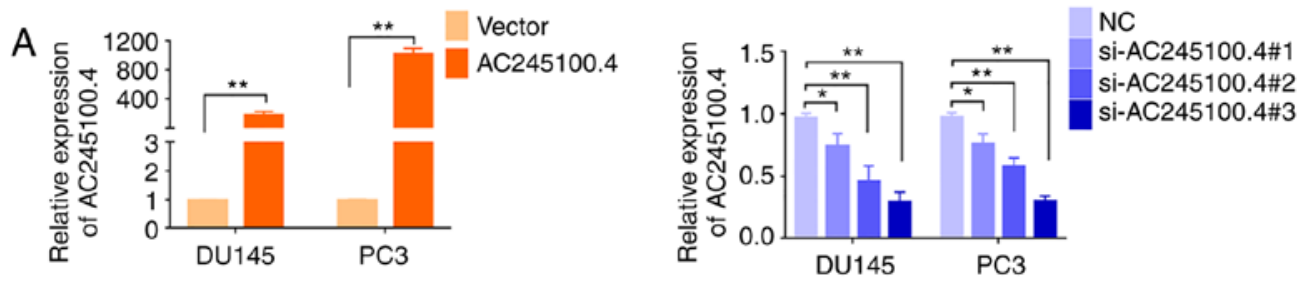

B

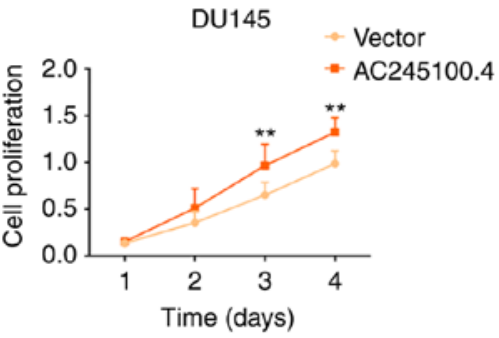

C

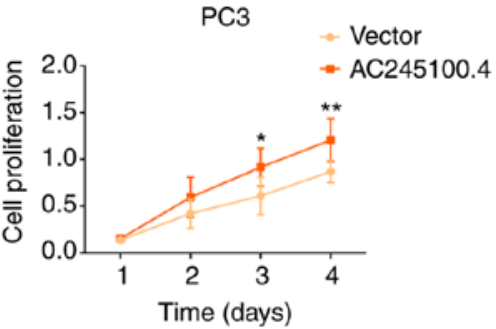

D
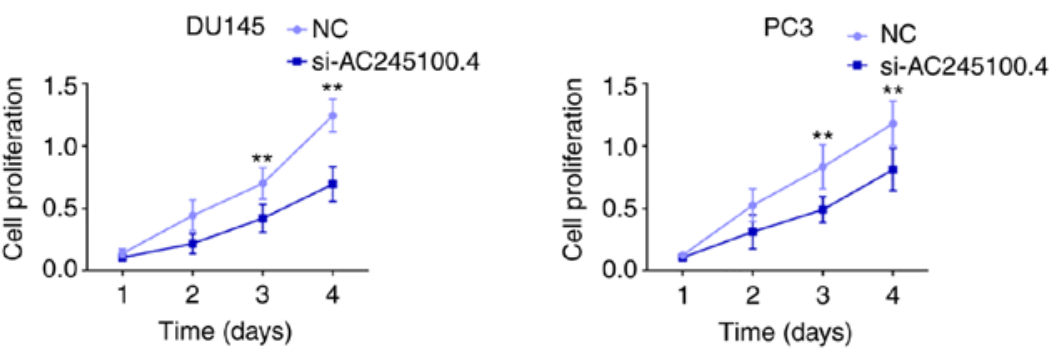

$\mathrm{E}$
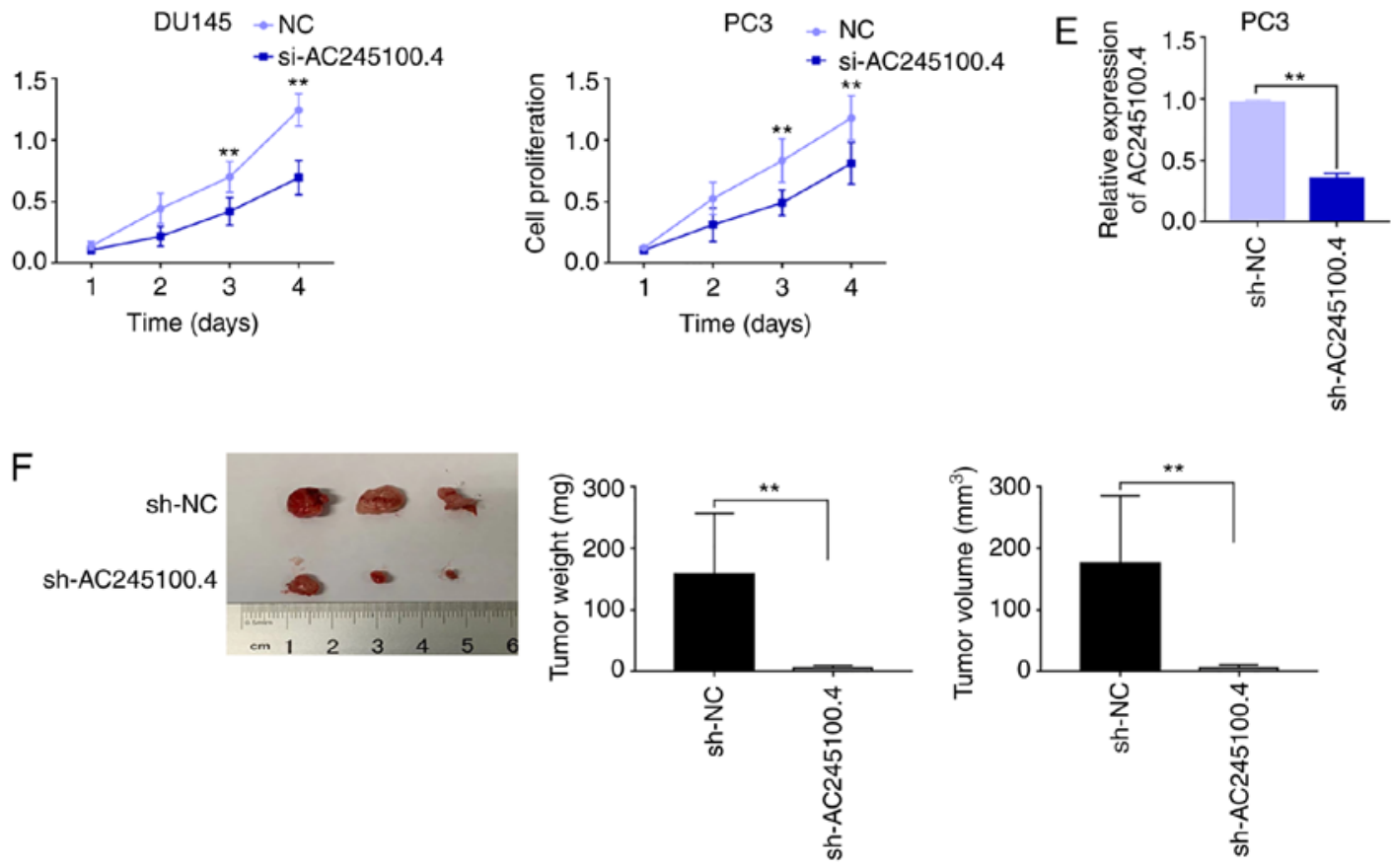

Figure 2. IncRNA AC245100.4 promotes PCa cell proliferation in vitro and in vivo. (A) DU145 and PC3 cells transfected with si-AC245100.4 or pcDNA3.1-AC245100.4 were analyzed for lncRNA expression via RT-qPCR. Effects of AC245100.4 (B and C) overexpression or (D) knockdown on PCa cell proliferation were assessed using Cell Counting Kit 8 assays. ${ }^{*} \mathrm{P}<0.05$ and ${ }^{* *} \mathrm{P}<0.01$ Comparison of cell proliferation at indicated time point. ${ }^{*} \mathrm{P}<0.05$ and ${ }^{* *} \mathrm{P}<0.01 \mathrm{Si}-\mathrm{AC} 245100.4$ vs. NC or AC245100.4 vs. vector. (E) PC3 cells transfected with sh-AC245100.4 were analyzed for lncRNA expression via RT-qPCR. (F) Tumor volume and weight were detected in a xenograft mouse model established via subcutaneous injection of sh-control-transfected and sh-AC245100.4-transfected PC3 cells. Data are presented as the mean \pm SD of three independent experiments $(\mathrm{n}=3)$. " $\mathrm{P}<0.05$ and ${ }^{* * *} \mathrm{P}<0.01$. AC245100.4, lncRNA AC245100.4; lncRNA, long non-coding RNA; PCa, prostate cancer; si, small interfering RNA; sh, short hairpin RNA; RT-qPCR, reverse transcription-quantitative PCR; NC, negative control.

decrease miR-145-5p expression, and transfection with miR-145-5p mimic could significantly increase miR-145-5p expression (Fig. 4C). Furthermore, AC245100.4 expression was downregulated by exogenous miR-145-5p mimic transfection, but upregulated by miR-145-5p inhibitor transfection (Fig. 4D).

To confirm the direct binding, luciferase reporter assays were conducted. A vector containing the AC245100.4/miR$145-5 p$ binding sequence (AC WT) and a vector with the deleted binding site (AC MUT) were generated. Vectors were transfected together with miR-145-5p mimics. The luciferase activity was decreased following co-transfection of miR-145-5p mimic and AC WT reporter vector, but remained unchanged for AC MUT vector (Fig. 4E), which indicated that AC245100.4 may be a target of miR-145-5p.

AC245100.4 and miR-145-5p both bind to AGO2 in PCa cells. miRNAs exert their gene silencing function by binding to AGO2, forming a functional RISC, and miRNAs degrade mRNAs with the involvement of RISC (25). To further verify the present hypothesis, anti-AGO2 RIP was performed using PC3 cell extracts. RT-qPCR was used to determine whether AC245100.4 and miR-145-5p were present in the immunoprecipitates. AC245100.4 was enriched in anti-AGO2 conjugated immunoprecipitates compared with in the anti-IgG control. Consistently, miR-145-5p was also present in the 
A
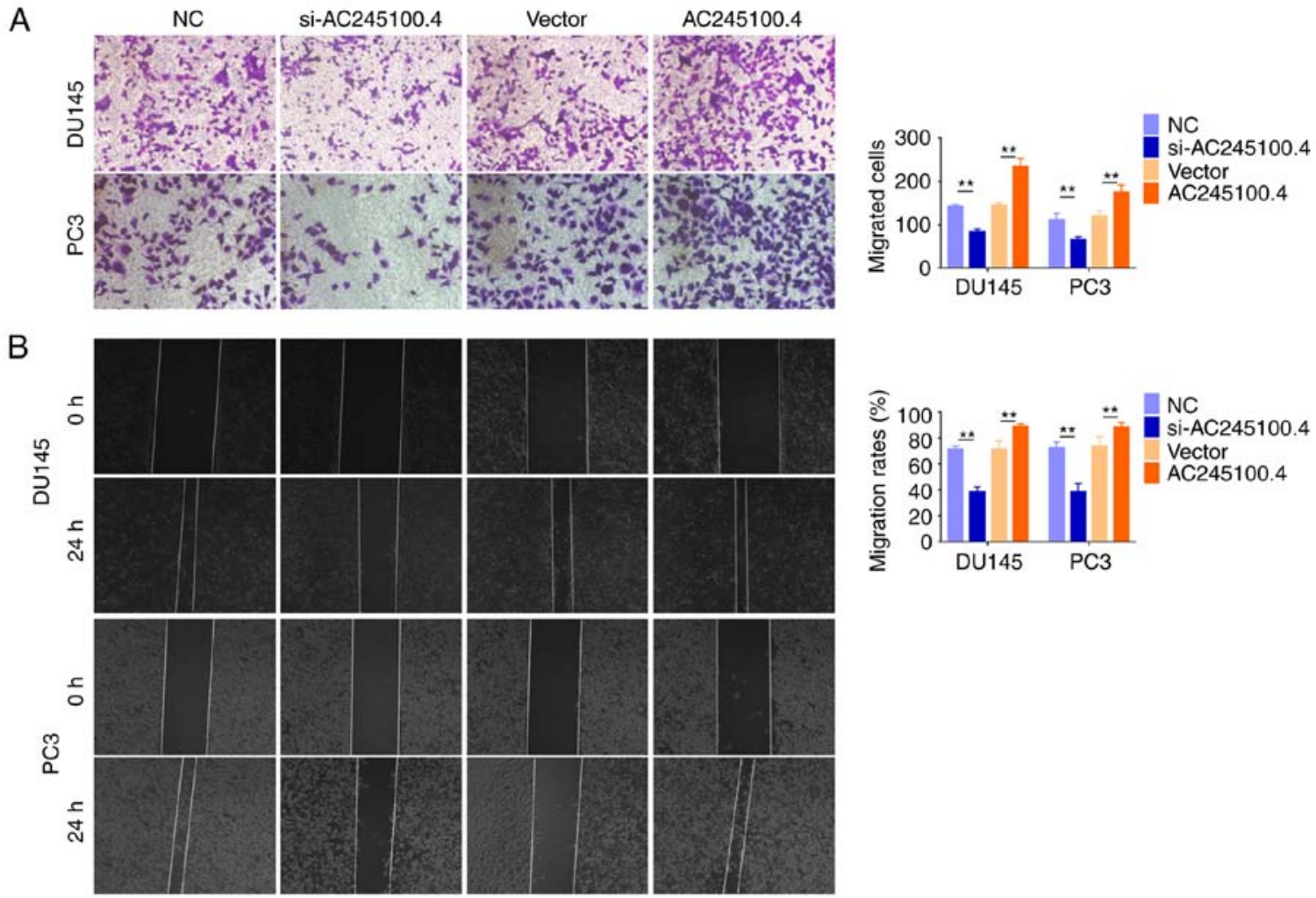

Figure 3. IncRNA AC245100.4 promotes PCa cell migration in vitro. (A) Effects of AC245100.4 on PCa cell migration were assessed using Transwell migration and (B) wound healing assays. Magnification, $x 200$. Data are presented as the mean \pm SD of three independent experiments $(n=3) .{ }^{* *} \mathrm{P}<0.01$. AC245100.4, lncRNA AC245100.4; lncRNA, long non-coding RNA; PCa, prostate cancer; NC, negative control; si, small interfering RNA.

\section{A AC245100.4 WT 5'-agauccuugucaGAAAACUu-3' miR-145-5p 3'-ucccuaaggaccCUUUUUGÁc-5' AC245100.4 MUT 5'-agauccuugucaGAAAAGUU-3'}
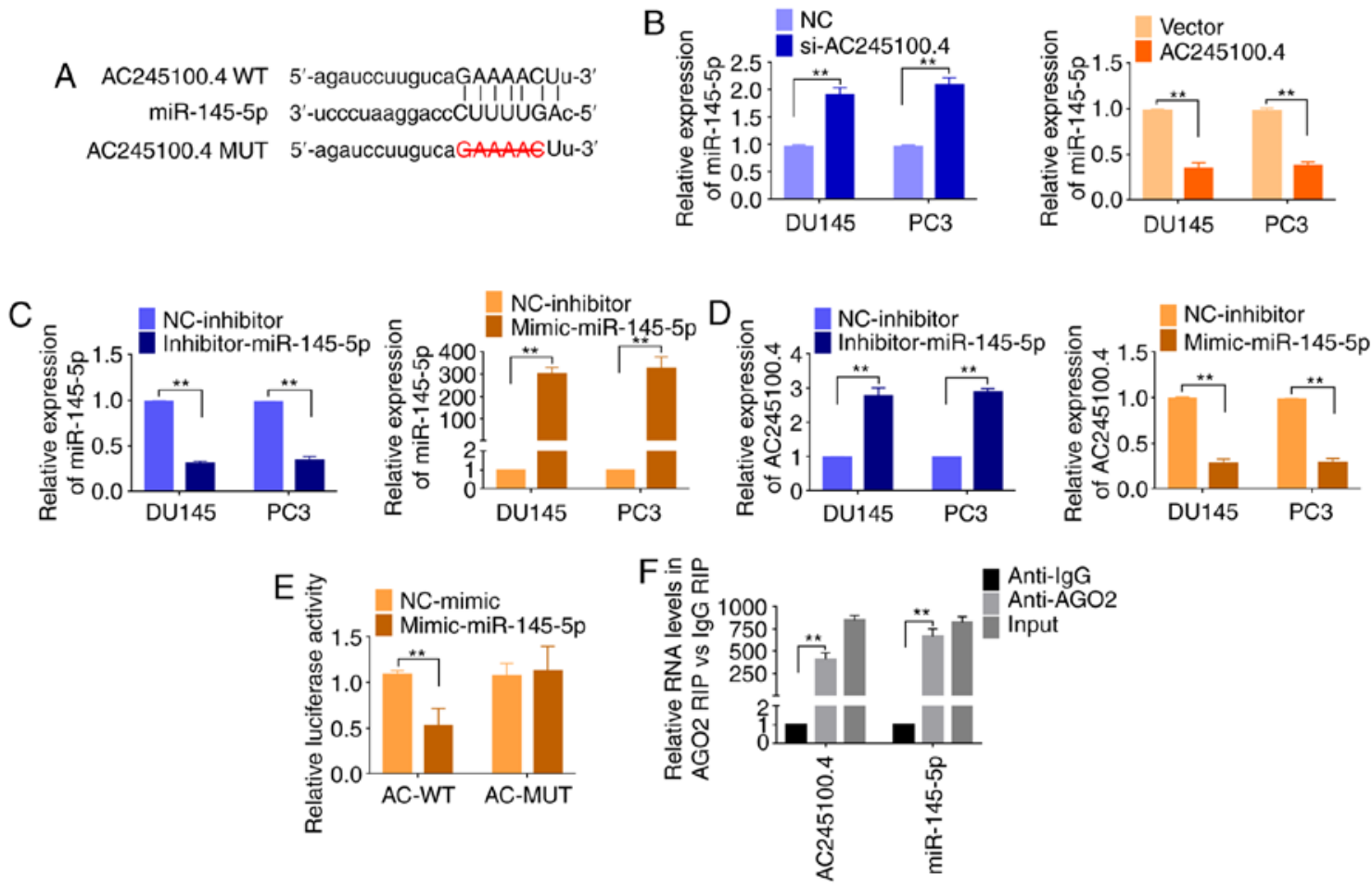

Figure 4. miR-145-5p targets AC245100.4 in PCa. (A) Bioinformatics analysis demonstrated that miR-145-5p directly targeted the AC245100.4 sequence. (B) RT-qPCR analysis of miR-145-5p expression in DU145 and PC3 cells transfected with AC245100.4 si-RNA or pcDNA3.1-AC245100.4. (C) RT-qPCR analysis of miR-145-5p expression in DU145 and PC3 cells transfected with miR-145-5p mimic or inhibitor. (D) RT-qPCR analysis of AC245100.4 expression in DU145 and PC3 cells transfected with miR-145-5p mimic or inhibitor. (E) Luciferase reporter plasmid containing AC-WT or AC-MUT AC245100.4 was co-transfected into 293T cells with miR-145-5p mimic or NC. (F) RIP experiments were performed in PC3 cells, and the coprecipitated RNA was subjected to RT-qPCR for analysis of AC245100.4 and miR-145-5p expression. ${ }^{* *} \mathrm{P}<0.01 \mathrm{vs.} \mathrm{IgG}$. Data are presented as the mean \pm SD of three independent experiments $(\mathrm{n}=3) .{ }^{* *} \mathrm{P}<0.01$. AC-WT, AC245100.4 wild-type; AC-MUT, AC245100.4 mutant; miR-145-5p, microRNA-145-5p; PCa, prostate cancer; RT-qPCR, reverse transcription-quantitative PCR; NC, negative control; si, small interfering RNA; AGO2, catalytic component; RIP, RNA immunoprecipitation. 
A RBBP5 WT 5'-cuGuAaUCCCaGcuAcACUGGAg-3' miR-145-5p 3'-ucCcUaAGGacCcuUuUGACCUg-5 RBBP5 MUT 5'-cuGuAaUCCcaGcuAcAGUGGAg-3'
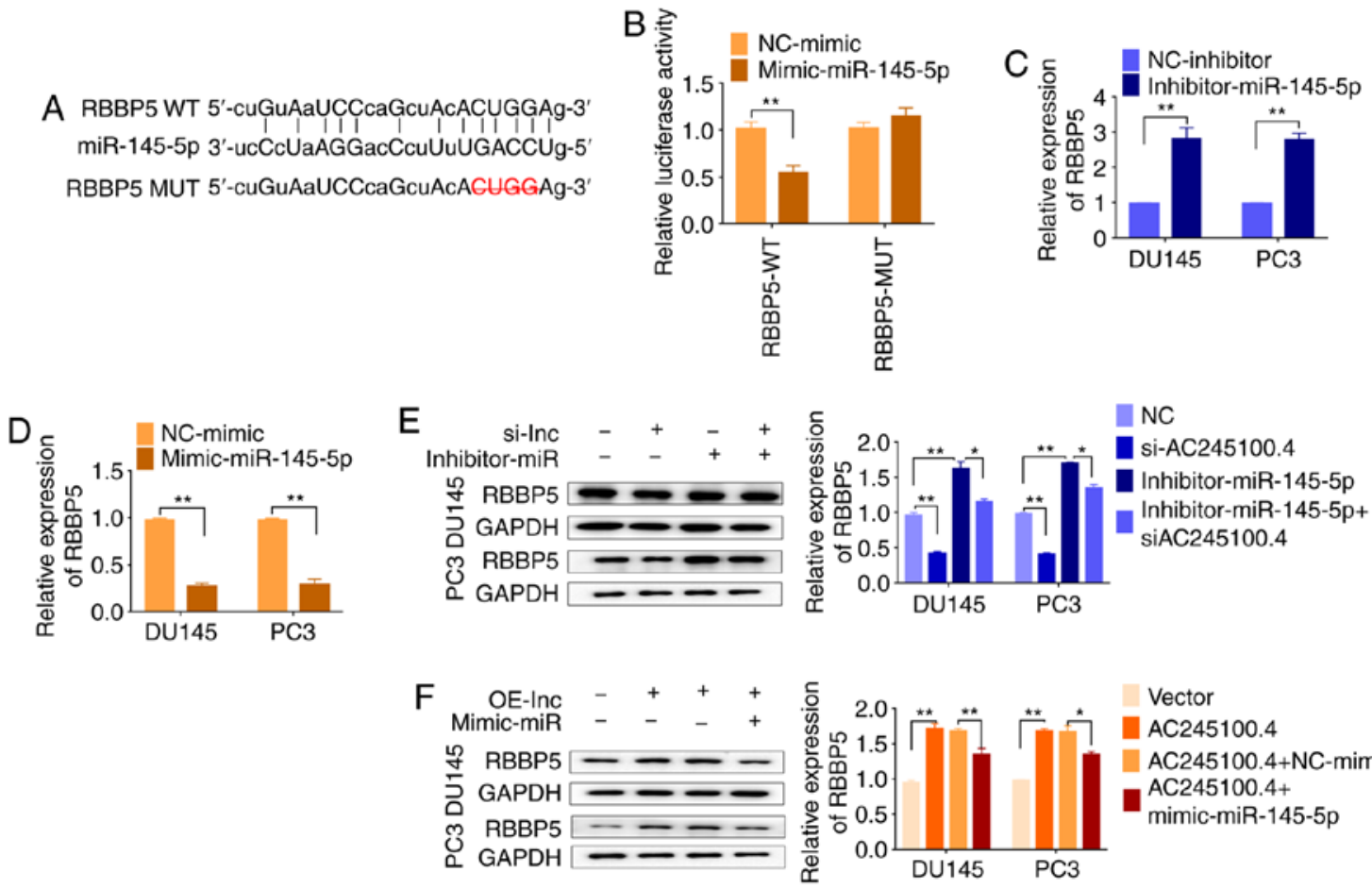

Vector

AC245100.4

AC245100.4+NC-mimic

AC245100.4+

mimic-miR-145-5p

Figure 5. RBBP5 is a miR-145-5p target gene and is indirectly regulated by AC245100.4. (A) Bioinformatics analysis demonstrated that RBBP5 is a target gene of miR-145-5p. (B) Luciferase reporter plasmid containing RBBP5-WT or RBBP5-MUT 3'untranslated region of RBBP5 was co-transfected into 293T cells with miR-145-5p mimic or NC. Reverse transcription-quantitative PCR analysis of RBBP5 expression in DU145 and PC3 cells transfected with miR-145-5p (C) inhibitor or (D) mimic. RBBP5 protein expression was analyzed via western blotting in DU145 and PC3 cells following (E) knockdown or (F) overexpression of AC245100.4 and co-transfection with miR-145-5p inhibitor or mimic. GAPDH was used as an internal control. Data are presented as the mean \pm SD of three independent experiments $(\mathrm{n}=3)$. ${ }^{*} \mathrm{P}<0.05$ and ${ }^{* *} \mathrm{P}<0.01$. OE-lnc, AC245100.4 overexpression; si-lnc, si-AC245100.4; Inhibitor-miR, Inhibitor-miR-145-5p; Mimic-miR, mimic-miR-145-5p; RBBP5, retinoblastoma binding protein 5; miR-145-5p, microRNA-145-5p; WT, wild-type; MUT, mutant; NC, negative control; si, small interfering RNA; lnc, long non-coding RNA.

immunoprecipitates (Fig. 4F). Therefore, AC245100.4 and miR-145-5p were both pulled down by AGO2, likely via direct binding. Overall, the present study suggested that there was direct binding between AC245100.4 and miR-145-5p, and demonstrated the reciprocal association between AC245100.4 and miR-145-5p.

IncRNA AC245100.4 regulates RBBP5 expression indirectly by sponging miR-145-5p. To elucidate the ceRNA network among AC245100.4, miR-145-5p and its targets in PCa, online prediction was conducted. TargetScan predicted 907 targets and miRDB predicted 909 targets $(21,22)$. There were $100 \mathrm{~s}$ of genes even after the results were overlapped. RBBP5 was among the overlapping genes. To validate the predicted relationships, luciferase assays were performed. The WT reporter vector contained RBBP5 3'UTR binding sites, but the binding sites were deleted in the MUT reporter vector (Fig. 5A). The luciferase activity was decreased after co-transfection of miR-145-5p mimic and the RBBP5 WT reporter vector, but not the MUT vector, indicating that miR-145-5p targeted RBBP5 by directly binding to the 3'UTR of RBBP5 (Fig. 5B). Additionally, miR-145-5p negatively regulated RBBP5 expression (Fig. 5C-F). It was also identified that knockdown or overexpression of AC245100.4 decreased or increased RBBP5 protein expression, respectively, in DU145 and PC3 cells (Fig. 5E and F).

Subsequently, it was investigated whether miR-145-5p was involved in the combination of AC245100.4 and RBBP5. As presented in Fig. 5E and F, RBBP5 expression was restored by miR-145-5p inhibition in AC245100.4-knockdown cells. Similarly, the increase in RBBP5 protein expression induced by AC245100.4 overexpression was effectively reversed by miR-145-5p mimics. Collectively, these findings suggested that AC245100.4 regulated the expression of RBBP5 via regulation of miR-145-5p at the post-transcriptional level.

lncRNA AC245100.4 reverses the suppressive role of $m i R-145-5 p$ in PCa. It was further investigated whether miR-145-5p suppressed tumorigenesis in DU145 and PC3 cells. The proliferation and migration of $\mathrm{PCa}$ cells were negatively associated with miR-145-5p expression (Fig. 6A-E).

To examine the reciprocal effects of miR-145-5p on AC245100.4, loss of function experiments were performed in $\mathrm{PCa}$ cells. The results demonstrated that cell proliferation in the inhibitor-miR-145-5p and si-AC245100.4 group was significantly decreased compared with the inhibitor-miR-145-5p group, suggesting that miR-145-5p silencing had promoting effect on proliferation, and this was partially reversed by AC245100.4 knockdown (Fig. 7A). The cell migration in the inhibitor-miR-145-5p and si-AC245100.4 group was significantly decreased compared with the inhibitor-miR-145-5p group, suggesting that the addition of the si-AC245100.4 altered the inhibitor-miR-145-5p-mediated increase in cell migration (Fig. 7B). All data suggested that miR-145-5p suppressed tumorigenesis in $\mathrm{PCa}$ and competed with AC245100.4 to exert its inhibitory effect in PCa cells. 
A
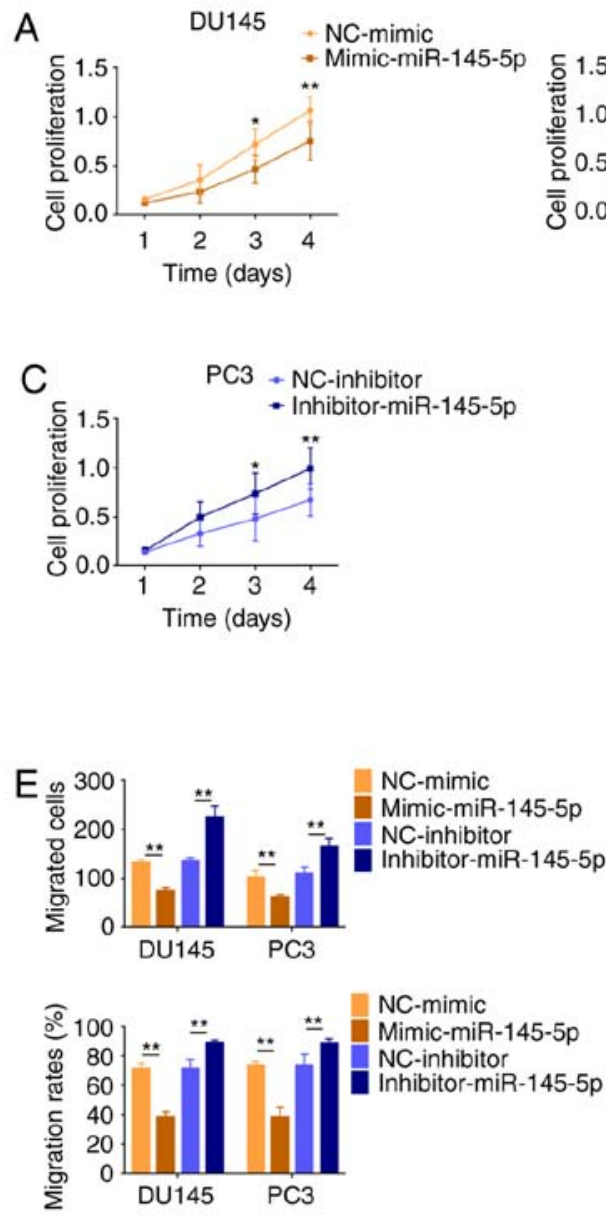
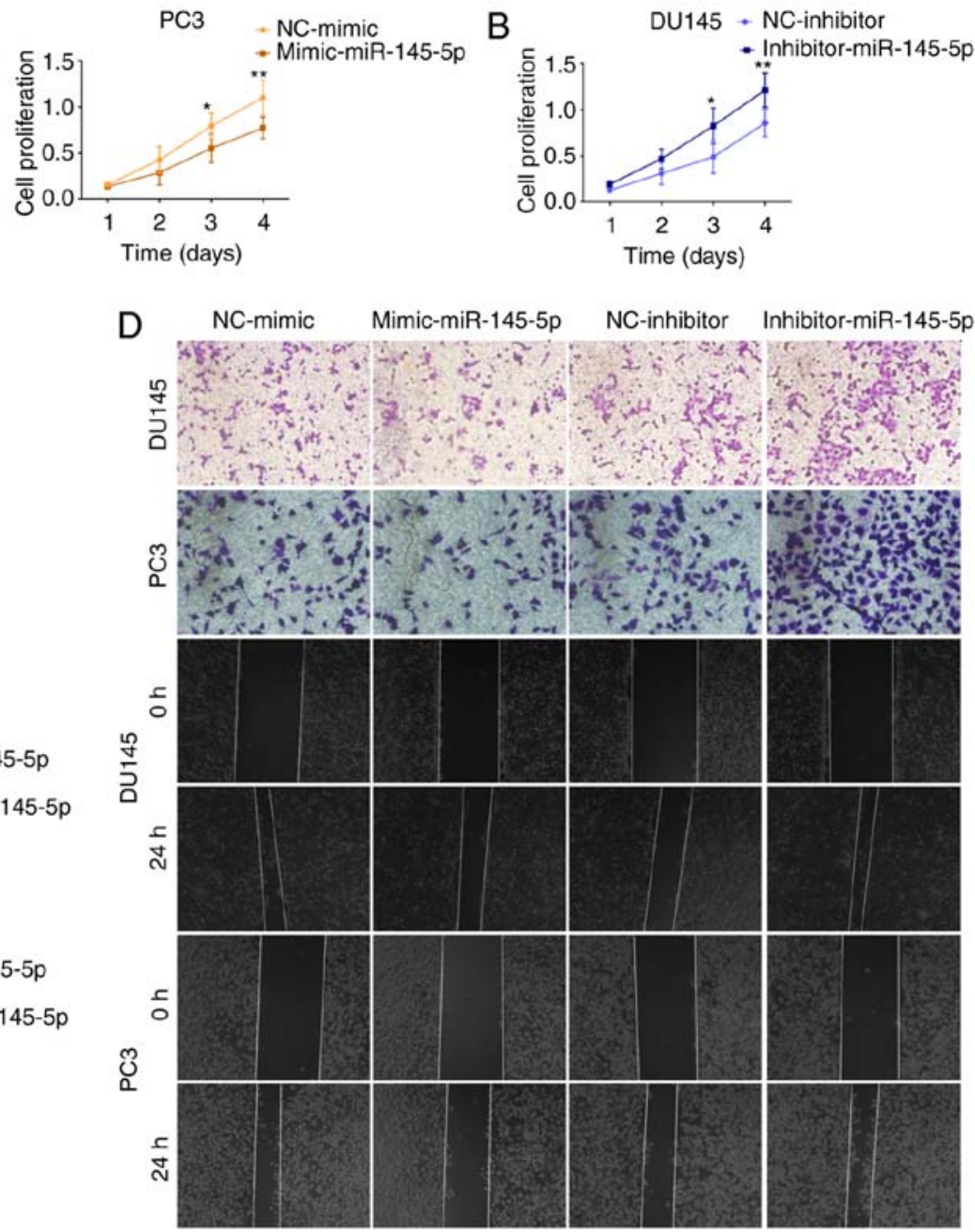

Figure 6. miR-145-5p serves as a tumor suppressor in PCa. Effects of miR-145-5p (A) mimic or (B and C) inhibitor on PCa cell proliferation were assessed using a Cell Counting Kit 8 assay. (D) Effects of miR-145-5p on PCa cell migration were assessed using Transwell migration and wound healing assays, (E) and the results were quantified. Magnification, $\mathrm{x} 200$. Data are presented as the mean $\pm \mathrm{SD}$ of three independent experiments $(\mathrm{n}=3)$. ${ }^{*} \mathrm{P}<0.05$ and ${ }^{* *} \mathrm{P}<0.01$. miR-145-5p, microRNA-145-5p; PCa, prostate cancer; NC, negative control.

\section{Discussion}

PCa was the second most common newly diagnosed cancer and fifth leading cause of cancer-associated mortality in men worldwide in 2018 (4). Therefore, a comprehensive understanding of the molecular events responsible for $\mathrm{PCa}$ tumorigenesis is required. 1ncRNAs have gained increasing attention as cryptic regulators in $\mathrm{PCa}(9)$. Thus, it is necessary to identify the underlying mechanisms of these regulatory transcripts to fully understand $\mathrm{PCa}$ carcinogenesis in order to develop novel diagnostic targets and treatment strategies.

In the present study, a novel IncRNA, AC245100.4, associated with PCa was identified. Upregulated expression levels of AC245100.4 were observed in tumor tissues in TCGA data and cell lines. The results demonstrated that AC245100.4 had an oncogenic effect on PCa cell proliferation and migration. AC245100.4 exerted its oncogenic role by sponging miR-145-5p, thereby repressing degradation of RBBP5. The present findings provided evidence for AC245100.4 as a candidate for overcoming therapeutic obstacles in PCa.
Previous studies have reported that lncRNAs are responsible for PCa carcinogenesis (9). For example, PCA3, metastasis associated lung adenocarcinoma transcript 1 (MALAT1), HOX transcript antisense RNA and prostate cancer associated transcript (PCAT)19 serve oncogenic roles and promote growth in PCa, while PCAT29 and Downregulated RNA in Androgen Independent Cells suppress cellular migration and metastasis $(8,26)$. Certain characterized lncRNAs, such as PCA3, H19 and PCAT29, have been considered to be more specific to $\mathrm{PCa}$ (8). Our previous study predicted that AC245100.4 was closely associated with PCa using bioinformatics methods (17). In the present study, AC245100.4 was demonstrated to promote proliferation and migration in $\mathrm{PCa}$ cell lines, and to induce tumor growth in an animal model. Upregulated expression levels of AC245100.4 were observed in TCGA tumor samples. To the best of our knowledge, this was the first study to identify the oncogenic function of AC245100.4 in PCa. However, the expression levels of AC245100.4 should be studied in additional patients in future studies.

A number of lncRNAs exert their function by acting as ceRNAs in PCa $(14,15,17)$. In ceRNA networks, miRNAs are 
A

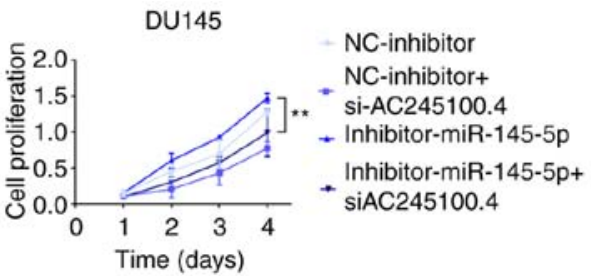

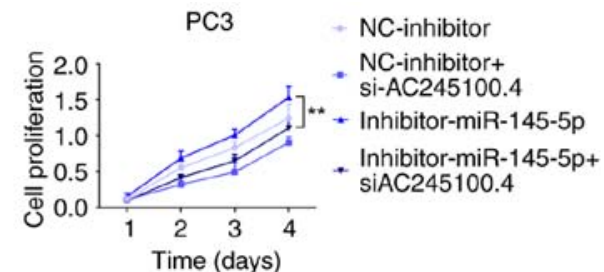
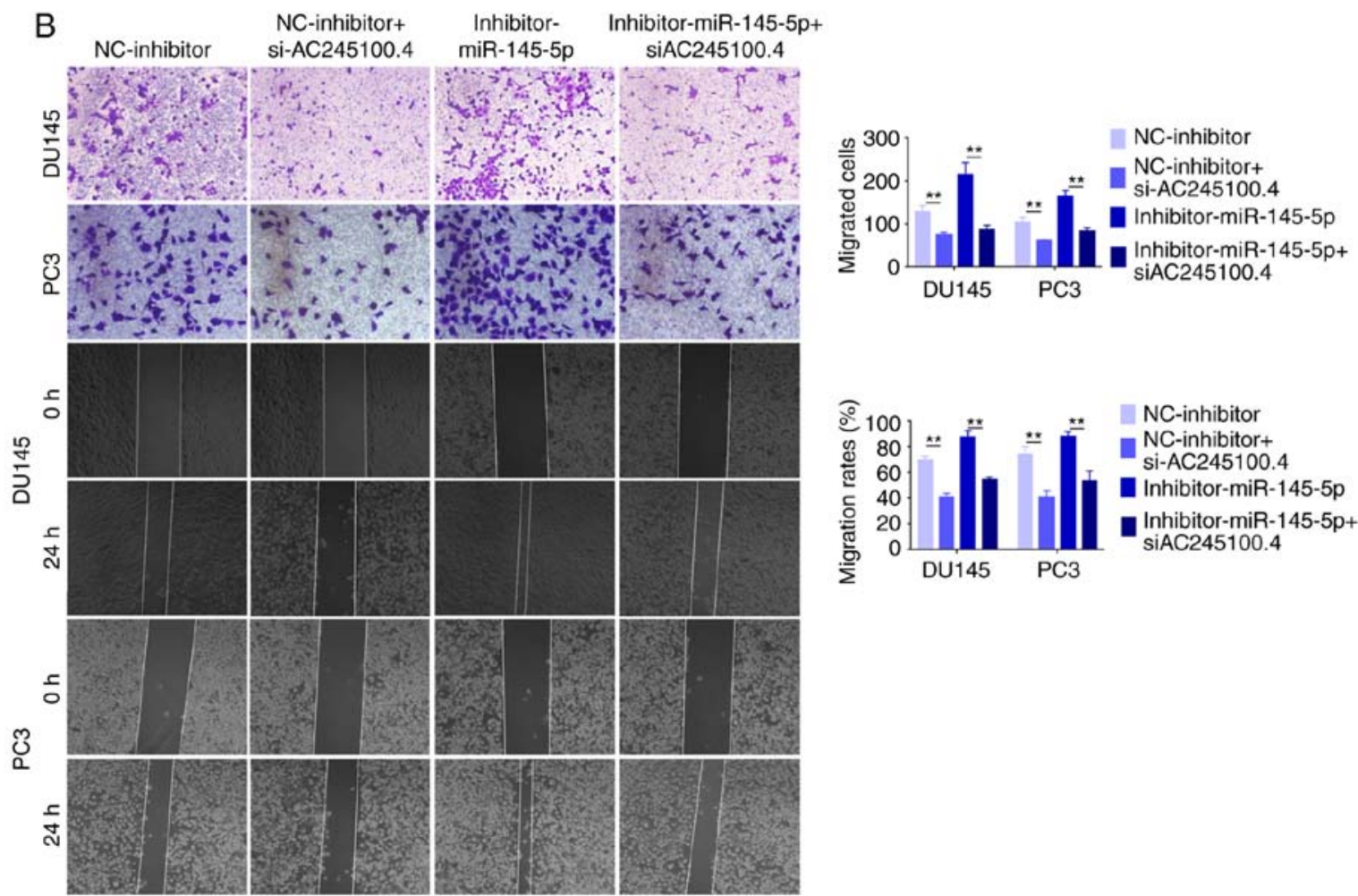

Figure 7. IncRNA AC245100.4 activity is partially mediated via negative regulation of miR-145-5p. (A) Proliferation of DU145 and PC3 cells following co-transfection with si-AC245100.4 and miR-145-5p inhibitor was determined using a Cell Counting Kit 8 assay. (B) Cell migration of DU145 and PC3 cells after co-transfection with si-AC245100.4 and miR-145-5p inhibitor was determined using Transwell migration and wound healing assays. Magnification, $\mathrm{x} 200$. Data are presented as the mean \pm SD of three independent experiments $(n=3)$. ${ }^{* *} \mathrm{P}<0.01$. lncRNA, long non-coding RNA; miR-145-5p, microRNA-145-5p; si, small interfering RNA; NC, negative control.

important mediators, and miRNAs could serve roles in $\mathrm{PCa}$ development, and thus are potential targets for novel therapies $(27,28)$. There has been increased interested in ncRNAs (miRNAs and lncRNAs) due to limitations of coding genes in cancer diagnosis and treatment (29). IncRNA-miRNA ceRNA networks represents the competitive association between IncRNAs and miRNAs, which could explain some features of PCa. For example, lncRNA HLA complex P5 expression is upregulated in $\mathrm{PCa}$, and promotes cell proliferation by inducing cell migration inducing hyaluronidase 1 expression by sponging miR-4656 (30).

In the present study, an online database of biological information predicted that AC245100.4 had complementary binding sites with miR-145-5p. The direct binding was further confirmed using a luciferase reporter assay. Both AC245100.4 and miR-145-5p could interact with AGO2 in PCa cells, which suggested that AC245100.4 may function as an endogenous miRNA sponge. Numerous studies have revealed that miR-145-5p suppresses tumor progression in various types of cancer, including melanoma, NSCLC, bladder cancer and gastric cancer (31-33). In PCa, miR-145-5p inhibits docetaxel resistance by repressing A-kinase anchoring protein 12, which could be reversed by MALAT1 in a ceRNA manner (34). Furthermore, the miR-145-5p/fascin actin-bundling protein 1 axis contributes to tumor progression mediated by PCAT1, and PCAT1 competes with miR-145-5p by direct binding (35). The functions of miRNAs largely depend on the specific target, thus the molecular mechanism of miR-145-5p was also a focus of the present study. It was demonstrated that PCa cell proliferation and migration were impaired following transfection of miR-145-5p mimics. Moreover. AC245100.4 promoted the proliferation and migration of DU145 and PC3 cells by targeting miR-145-5p. It is important to identify real markers and develop novel specific therapies to decrease the mortality of PCa (36). Therefore, further study of miRNAs is important (37). The present findings reinforced the tumor-suppressive role of miR-145-5p in $\mathrm{PCa}$, which suggests it as a promising biomarker.

The ceRNA network also requires a miRNA target gene to complete the regulatory axis (10). According to bioinformatics analyses, RBBP5 and AC245100.4 share the same response elements for miR-145-5p. The association was verified 
using luciferase reporter assays. Furthermore, miR-145-5p expression was negatively associated with RBBP5 protein expression. It was identified that knockdown or overexpression of AC245100.4 decreased or increased RBBP5 protein expression. Therefore, it was demonstrated that RBBP5 was targeted by miR-145-5p. AC245100.4 may induce RBBP5 expression by repressing its inhibitor, miR-145-5p. RBBP5 is a coding protein in the nucleus (38), and can bind to RB transcriptional corepressor 1, a known tumor suppressor (39). However, the role of RBBP5 is ambiguous. Increased RBBP5 expression has been observed in patients with hepatocellular carcinoma, and RBBP5 knockdown can inhibit the proliferation of hepatocellular carcinoma cells (40). Moreover, RBBP5 silencing promotes cell adhesion and migration in cervical cancer cells (41). These findings indicate that RBBP5 has dual roles in cancer. The exact role and underlying mechanism of RBBP5 in PCa should be investigated in future studies.

In conclusion, the present study demonstrated that the novel lncRNA AC245100.4 was upregulated in PCa cells and may be involved in the development of PCa. High AC245100.4 expression may be one of the factors affecting the prognosis of patients with PCa. Mechanistically, AC245100.4 can regulate the expression of RBBP5, acting as a ceRNA of miR-145-5p. The present findings provide evidence that AC245100.4 may be a promising diagnostic or therapeutic marker for $\mathrm{PCa}$.

\section{Acknowledgements}

Not applicable.

\section{Funding}

The present study was supported by the National Natural Science Foundation of China (grant no. 81572535), China Postdoctoral Science Foundation (grant no. 2019M651297) and The Fundamental Research Funds for the Provincial Universities of Heilongjiang (grant no. 2018-KYYWF-0432).

\section{Availability of data and materials}

The datasets used and/or analyzed during the current study are available from the corresponding author on reasonable request.

\section{Authors' contributions}

HX and JBZ contributed equally. XGY and PL designed and supervised the study. JNZ, QQW, XY and WYY performed the in vitro experiments. HX and JBZ analyzed the data and wrote the manuscript. JHW performed the bioinformatics analysis. All authors read and approved the final manuscript.

\section{Ethics approval and consent to participate}

The animal experiments were approved by the Animal Ethics Committee of Harbin Medical University (Harbin, China).

\section{Patient consent for publication}

Not applicable.

\section{Competing interests}

The authors declare that they have no competing interests.

\section{References}

1. Siegel RL, Miller KD and Jemal A: Cancer statistics, 2018. CA Cancer J Clin 68: 7-30, 2018.

2. Siegel RL and Miller KD: Cancer statistics, 2020. CA Cancer J Clin 70: 7-30, 2020.

3. Siegel RL and Miller KD: Cancer statistics, 2019. CA Cancer J Clin 69: 7-34, 2019.

4. Bray F, Ferlay J, Soerjomataram I, Siegel RL, Torre LA and Jemal A: Global cancer statistics 2018: GLOBOCAN estimates of incidence and mortality worldwide for 36 cancers in 185 countries. CA Cancer J Clin 68: 394-424, 2018.

5. Chen QN, Wei CC, Wang ZX and Sun M: Long non-coding RNAs in anti-cancer drug resistance. Oncotarget 8: 1925-1936, 2017.

6. Tehrani SS, Karimian A, Parsian H, Majidinia M and Yousefi B: Multiple functions of long non-coding RNAs in oxidative stress, DNA damage response and cancer progression. J Cell Biochem 119: 223-236, 2018.

7. Quinn JJ and Chang HY: Unique features of long non-coding RNA biogenesis and function. Nat Rev Genet 17: 47-62, 2016.

8. Ramnarine VR, Kobelev M, Gibb EA, Nouri M, Lin D, Wang Y, Buttyan R, Davicioni E, Zoubeidi A and Collins CC: The evolution of long noncoding RNA acceptance in prostate cancer initiation, progression, and its clinical utility in disease management. Eu Urol 76: 546-559, 2019.

9. Fatima R, Akhade VS, Pal D and Rao SM: Long noncoding RNAs in development and cancer: Potential biomarkers and therapeutic targets. Mol Cell Ther 3: 5, 2015.

10. Salmena L, Poliseno L, Tay Y, Kats L and Pandolfi PP: A ceRNA hypothesis: The Rosetta Stone of a hidden RNA language? Cell 146: 353-358, 2011.

11. Wu P, Cai J, Chen Q, Han B, Meng X, Li Y, Li Z, Wang R, Lin L, Duan $\mathrm{C}$, et al: Lnc-TALC promotes $\mathrm{O}^{6}$-methylguanine-DNA methyltransferase expression via regulating the c-Met pathway by competitively binding with miR-20b-3p. Nat Commun 10: 2045, 2019.

12. Wu XS, Wang F, Li HF, Hu YP, Jiang L, Zhang F, Li ML, Wang XA, Jin YP, Zhang YJ, et al: LncRNA-PAGBC acts as a microRNA sponge and promotes gallbladder tumorigenesis. EMBO Rep 18: 1837-1853, 2017.

13. Peng W, He D, Shan B, Wang J, Shi W, Zhao W, Peng Z, Luo Q, Duan M, Li B, et al: LINC81507 act as a competing endogenous RNA of miR-199b-5p to facilitate NSCLC proliferation and metastasis via regulating the CAV1/STAT3 pathway. Cell Death Dis 10: $533,2019$.

14. Zhang G, He X, Ren C, Lin J and Wang Q: Long noncoding RNA PCA3 regulates prostate cancer through sponging miR-218-5p and modulating high mobility group box 1 . J Cell Physiol 234 : 13097-13109, 2019.

15. Wu X, Xiao Y,Zhou Y,Zhou Z and Yan W: LncRNA FOXP4-AS1 is activated by PAX 5 and promotes the growth of prostate cancer by sequestering miR-3184-5p to upregulate FOXP4. Cell Death Dis 10: 472, 2019.

16. Cheng G, Song Z, Liu Y, Xiao H, Ruan H, Cao Q, Wang K, Xiao W, Xiong Z, Liu D, et al: Long noncoding RNA SNHG12 indicates the prognosis of prostate cancer and accelerates tumorigenesis via sponging miR-133b. J Cell Physiol 235: 1235-1246, 2020.

17. Liu Y, Zhang R, Zhao N, Zhang Q, Yan Z, Chang Z, Wei Y, Wu C, Xu J and Xu Y: A comparative analysis reveals the dosage sensitivity and regulatory patterns of lncRNA in prostate cancer. Mol Biosyst 12: 3176-3185, 2016.

18. Tang Z, Li C, Kang B, Gao G, Li C and Zhang Z: GEPIA: A web server for cancer and normal gene expression profiling and interactive analyses. Nucleic Acids Res 45: W98-W102, 2017.

19. Livak KJ and Schmittgen TD: Analysis of relative gene expression data using real-time quantitative PCR and the 2(-Delta Delta C(T)) method. Methods 25: 402-408, 2001.

20. Zhang H, Jiang M, Liu Q, Han Z, Zhao Y and Ji S: miR-145-5p inhibits the proliferation and migration of bladder cancer cells by targeting TAGLN2. Oncol Lett 16: 6355-6360, 2018. 
21. Chen Y and Wang X: miRDB: An online database for prediction of functional microRNA targets. Nucleic Acids Res 48 D127-D131, 2020.

22. Agarwal V, Bell GW, Nam JW and Bartel DP: Predicting effective microRNA target sites in mammalian mRNAs. Elife 4 e05005, 2015.

23. Paraskevopoulou MD, Vlachos IS, Karagkouni D, Georgakilas G Kanellos I, Vergoulis T, Zagganas K, Tsanakas P, Floros E, Dalamagas $\mathrm{T}$ and Hatzigeorgiou AG: DIANA-LncBase v2: Indexing microRNA targets on non-coding transcripts. Nucleic Acids Res 44: D231-D238, 2016.

24. Aiello NM and Kang Y: Context-dependent EMT programs in cancer metastasis. J Exp Med 216: 1016-1026, 2019.

25. Golden RJ, Chen B, Li T, Braun J, Manjunath H, Chen X, Wu J, Schmid V, Chang TC, Kopp F, et al: An Argonaute phosphorylation cycle promotes microRNA-mediated silencing. Nature 542. 197-202, 2017.

26. Sakurai K, Reon BJ, Anaya J and Dutta A: The lncRNA DRAIC/PCAT29 locus constitutes a tumor-suppressive nexus. Mol Cancer Res 13: 828-838, 2015.

27. Cochetti G, Poli G, Guelfi G, Boni A, Egidi MG and Mearini E: Different levels of serum microRNAs in prostate cancer and benign prostatic hyperplasia: Evaluation of potential diagnostic and prognostic role. OncoTargets Ther 9: 7545-7553, 2016.

28. Guelfi G, Cochetti G, Stefanetti V, Zampini D, Diverio S, Boni A and Mearini E: Next generation sequencing of urine exfoliated cells: An approach of prostate cancer microRNAs research. Sci Rep 8: 7111, 2018.

29. Egidi MG, Cochetti G, Serva MR, Guelfi G, Zampini D, Mechelli L and Mearini E: Circulating microRNAs and kallikreins before and after radical prostatectomy: Are they really prostate cancer markers? Biomed Res Int 2013: 241780, 2013

30. Hu R and Lu Z: Long non-coding RNA HCP5 promotes prostate cancer cell proliferation by acting as the sponge of miR-4656 to modulate CEMIP expression. Oncol Rep 43: 328-336, 2020.

31. Jin C, Wang A, Liu L, Wang G, Li G and Han Z: miR-145-5p inhibits tumor occurrence and metastasis through the NF- $\mathrm{KB}$ signaling pathway by targeting TLR4 in malignant melanoma. J Cell Biochem: Jan 30, 2019 (Epub ahead of print).

32. Lu Q, Shan S, Li Y, Zhu D, Jin W and Ren T: Long noncoding RNA SNHG1 promotes non-small cell lung cancer progression by up-regulating MTDH via sponging miR-145-5p. FASEB J 32: $3957-3967,2018$
33. Sun M, Zhao W, Chen Z, Li M, Li S, Wu B and Bu R: Circular RNA CEP128 promotes bladder cancer progression by regulating Mir-145-5p/Myd88 via MAPK signaling pathway. Int J Cancer 145: 2170-2181, 2019.

34. Xue D, Lu H, Xu HY, Zhou CX and He XZ: Long noncoding RNA MALAT1 enhances the docetaxel resistance of prostate cancer cells via miR-145-5p-mediated regulation of AKAP12. J Cell Mol Med 22: 3223-3237, 2018.

35. Xu W, Chang J, Du X and Hou J: Long non-coding RNA PCAT-1 contributes to tumorigenesis by regulating FSCN1 via miR-145-5p in prostate cancer. Biomed Pharmacother 95: 1112-1118, 2017.

36. Egidi MG and Cochetti G: Stability assessment of candidate reference genes in urine sediment of prostate cancer patients for miRNA applications. Dis Markers 2015: 973597, 2015.

37. Cochetti G, Rossi de Vermandois JA, Maulà V, Giulietti M, Cecati M, Del Zingaro M, Cagnani R, Suvieri C, Paladini A and Mearini E: Role of miRNAs in prostate cancer: Do we really know everything? Urol Oncol 38: 623-635, 2020.

38. Saijo M, Sakai Y, Kishino T, Niikawa N, Matsuura Y, Morino K, Tamai K and Taya Y: Molecular cloning of a human protein that binds to the retinoblastoma protein and chromosomal mapping. Genomics 27: 511-519, 1995.

39. Gallie BL, Campbell C, Devlin H, Duckett A and Squire JA: Developmental basis of retinal-specific induction of cancer by RB mutation. Cancer Res 59 (7 Suppl): 1731S-1735S, 1999.

40. Zhou H, Bao J, Zhu X, Dai G, Jiang X, Jiao X, Sheng H, Huang J and $\mathrm{Yu} \mathrm{H}$ : Retinoblastoma binding protein 5 correlates with the progression in hepatocellular carcinoma. BioMed Res Int 2018: 1073432,2018

41. Xia B, Joubert A, Groves B, Vo K, Ashraf D, Djavaherian D, Awe J, Xiong Y, Cherfils J and Ma D: Modulation of cell adhesion and migration by the histone methyltransferase subunit mDpy-30 and its interacting proteins. PLoS One 5: e11771, 2010.

(i) $\odot$ This work is licensed under a Creative Common Attribution-NonCommercial-NoDerivatives 4.0 International (CC BY-NC-ND 4.0) License. 